\title{
Posterior mitral leaflet extension: An adjunctive repair option for ischemic mitral regurgitation?
}

Frank Langer, MD, ${ }^{a}$ Filiberto Rodriguez, MD, ${ }^{a}$ Allen Cheng, MD, ${ }^{a}$ Saskia Ortiz, ${ }^{a}$ Tom C. Nguyen, MD, ${ }^{\text {a }}$ Mary K. Zasio, BA, ${ }^{a}$ David Liang, MD, PhD, ${ }^{b}$ George T. Daughters, $\mathrm{MS}^{\mathrm{a}, \mathrm{c}}$ Neil B. Ingels, $\mathrm{PhD},{ }^{\mathrm{a}, \mathrm{c}}$ and D. Craig Miller, $\mathrm{MD}^{\mathrm{a}}$

From the Department of Cardiothoracic Surgery and the Division of Cardiovascular Medicine, ${ }^{\mathrm{b}}$ Stanford University School of Medicine, Stanford, Calif, and the Laboratory of Cardiovascular Physiology and Biophysics, Research Institute of the Palo Alto Medical Foundation, ${ }^{\mathrm{c}}$ Palo Alto, Calif. Supported by Grants HL-29589 and HL-67025 from the National Heart, Lung and Blood Institute (NHLBI). Drs Langer, Rodriguez, and Cheng were Carl and Leah McConnell Cardiovascular Surgical Research Fellows. Dr Langer was also supported by the Deutsche Akademie der Naturforscher Leopoldina, Halle, Germany. Dr Rodriguez was supported by grant HL67025-01S1 from the NHLBI and was also a recipient of an American College of Surgeons Resident Research Scholarship Award. Drs Cheng and Nguyen were recipients of the Thoracic Surgery Foundation Research Fellowship Award.

Read at the 85th Annual Meeting of the American Association for Thoracic Surgery, San Francisco, Calif, April 2005.

Received for publication May 5, 2005; revisions received Oct 31, 2005; accepted for publication Nov 28, 2005.

Address for reprints: D. Craig Miller, MD, Department of Cardiothoracic Surgery, Falk Cardiovascular Research Center, Stanford University School of Medicine Manuscript, Stanford, CA 94305-5247 (E-mail: dcm@ stanford.edu).

J Thorac Cardiovasc Surg 2006;131:868-77 $0022-5223 / \$ 32.00$

Copyright (๑) 2006 by The American Association for Thoracic Surgery

doi:10.1016/j.jtcvs.2005.11.027
Background: Residual or recurrent mitral regurgitation frequently occurs after mitral valve repair for ischemic mitral regurgitation with an annuloplasty ring. Because annuloplasty primarily addresses annular dilatation, we studied an adjunctive technique that might correct restricted leaflet (Carpentier type IIIb) systolic closing motion, which often accompanies annular dilatation in patients with ischemic mitral regurgitation.

Methods: Six sheep had radiopaque markers placed on the left ventricle, mitral leaflets and annulus, and mitral subvalvular apparatus. A pericardial patch was sutured into the middle scallop of the posterior mitral valve leaflet and furled in with a reefing stitch placed in the radial axis. Posterolateral left ventricular myocardial ischemia was created by using proximal circumflex occlusion to induce acute ischemic mitral regurgitation. Under open-chest conditions, 3-dimensional marker coordinates were measured by using biplane videofluoroscopy at baseline and during acute ischemia both before and after release of the reefing stitch (leaflet extension); transesophageal echocardiography was used to grade ischemic mitral regurgitation.

Results: Leaflet apical systolic tethering was not improved by leaflet extension, but ischemic mitral regurgitation decreased (control, $0.9 \pm 0.3^{*}$; ischemia, $2.4 \pm 0.3$; leaflet extension, $1.5 \pm 0.3 ; * P<0.002$ ). Posterior mitral valve leaflet midline length (control, $1.45 \pm 0.09 *$; ischemia, $1.53 \pm 0.10$; leaflet extension, $1.83 \pm$ $0.13^{*} ; * P<0.001$ ) and posterior mitral valve leaflet middle scallop area (control, $1.66 \pm 0.20 \mathrm{~cm}^{2} *$; ischemia, $1.91 \pm 0.22 \mathrm{~cm}^{2}$; leaflet extension, $2.36 \pm 0.22 \mathrm{~cm}^{2} *$; $* P<0.006$ ) increased with leaflet extension because of patch unfurling (mean \pm 1 standard error of the mean; repeated-measures analysis of variance, Dunnet post-hoc test vs ischemia).

Conclusions: Posterior mitral valve leaflet extension ameliorated acute ischemic mitral regurgitation but did not correct the abnormal apically restricted systolic posterior mitral valve leaflet closing motion. This technique might be a useful adjunct repair in combination with ring annuloplasty for ischemic mitral regurgitation, but the clinical role of this adjunct remains to be defined in patients.

I schemic mitral regurgitation (IMR) is a frequent complication of myocardial infarction and is associated with a poor prognosis. ${ }^{1,2}$ Residual or recurrent mitral regurgitation (MR) is seen in upward of $30 \%$ of patients $^{3-6}$ after ring annuloplasty (RA), the most common repair technique used for IMR. Although a few groups have recently reported encouraging midterm results after undersized $\mathrm{RA}^{7-9}$ IMR remains a vexing problem in most other centers. Undersized annular reduction has been shown to correct both annular and subvalvular geometry in IMR ${ }^{10}$ but annular reduction with RA primarily addresses the annular dilatation component. The systolic leaflet tethering (LT) component of IMR (or Carpentier type 


$$
\begin{aligned}
& \text { Abbreviations and Acronyms } \\
& \begin{aligned}
\text { AML } & =\text { anterior mitral leaflet } \\
\text { ANOVA } & =\text { analysis of variance } \\
\text { 3-D } & =3 \text {-dimensional } \\
\text { IMR } & =\text { ischemic mitral regurgitation } \\
\text { LEX } & =\text { leaflet extension } \\
\text { LT } & =\text { leaflet tethering } \\
\text { LV } & =\text { left ventricular } \\
\text { MR } & =\text { mitral regurgitation } \\
\text { PML } & =\text { posterior mitral leaflet } \\
\text { PPM } & =\text { posterior papillary muscle } \\
\text { RA } & =\text { ring annuloplasty }
\end{aligned}
\end{aligned}
$$

IIIb restricted leaflet closing motion) caused by posterior papillary muscle displacement often persists and might even worsen with continued left ventricular (LV) remodeling, which can result in repair failure. ${ }^{4,5}$ Several investigators have proposed alternative repair techniques, but none of these techniques has received widespread clinical acceptance.

Although leaflet extension (LEX) has been used for patients with restricted leaflet motion resulting from rheumatic valve disease, ${ }^{11}$ it has only occasionally been used in patients with IMR. Dobre and coworkers ${ }^{12}$ reported 2 patients in whom extension of the posterior mitral leaflet (PML) with a pericardial patch was performed as an adjunct to RA. Based on this notion and the observation that persistent MR after RA is associated with increased LT of the PML, ${ }^{13}$ we tested the hypothesis that patch extension of the PML ameliorates LT and thereby reduces IMR in an ovine model of acute IMR without concomitant annular reduction.

\section{Methods}

\section{Surgical Preparation}

Six sheep $(66 \pm 4 \mathrm{~kg})$ were premedicated with ketamine (25 $\mathrm{mg} / \mathrm{kg}$ administered intramuscularly) and anesthetized with sodium thiopental $(6.8 \mathrm{mg} / \mathrm{kg}$ administered intravenously) and maintained with inhalational isoflurane (1\%-2.5\%). Through a left thoracotomy, miniature tantalum myocardial markers (nos. 2-14; Figure 1, A) were inserted in the LV subepicardium along 4 equally spaced longitudinal meridians, with one marker at the LV apex (no. 1; Fig 1, A). A snare was placed around the left circumflex coronary artery proximal to the first obtuse marginal branch.

On cardiopulmonary bypass (120 \pm 6 minutes), the ascending aorta was crossclamped $(89 \pm 5 \mathrm{~min})$, and the heart was arrested with retrograde crystalloid cardioplegia. Through a left atriotomy, miniature tantalum markers were placed at the tips and bases of both anterior and posterior papillary muscles (anterior papillary muscles nos. 28 and 29 and posterior papillary muscles 30 and 31). Eight markers were sutured around the circumference of the mitral annulus (one near each commissure [nos. 16 and 20] and 3 along the septal [nos. 15, 21, and 22] and lateral [nos. 17, 18, and 19] annulus; Figure 1, $A$ and $B$ ). Leaflet edge markers were sutured on the ventricular side of the anterior mitral leaflet (AML) and PML edges at the leaflet center (nos. 25 and 26; Figure 1, B). Markers were also sutured to the atrial side of the AML along the midline (nos. 23 and 24; Figure 1,B).

The middle scallop of the PML was detached from the annulus for a distance of approximately $15 \mathrm{~mm}$, preserving the attachments of the second-order chordae on the leaflet side of the incision. A pericardial patch was sized and sutured into this defect with a running 7-0 polypropylene suture. A gold marker (no. 27; Figure 1, B) was incorporated in the suture line in the PML midline to define the patch-leaflet junction. After completion of the suture lines, the patch was furled toward the annulus (Figure $1, C$ ) by using a 5-0 polypropylene reefing stitch, which was exteriorized through the left atrial wall, and a tourniquet.

The atriotomy was closed, the heart was deaired, the crossclamp was removed, and the heart was defibrillated (dopamine, $5.2 \pm 1.0 \mu \mathrm{g} \cdot \mathrm{kg}^{-1} \cdot \mathrm{min}^{-1}$ ). A pressure transducer (Millar SPC-500; Millar Instruments, Inc, Houston, Tex) was placed in the LV chamber through the apex.

\section{Experimental Protocol}

The animals were transferred to the catheterization laboratory and studied intubated with the chest open. Anesthesia was maintained with inhalational isoflurane (1\%-2.5\%). Animals received $100 \mathrm{mg}$ of lidocaine (administered intravenously) as prophylaxis against arrhythmias. Simultaneous biplane videofluoroscopic marker images and hemodynamic data were acquired at baseline (preischemia), during proximal circumflex ischemia (ischemia), and during ongoing ischemia after release of the patch reefing suture (patch extension; Figure 1, D). The severity of IMR was graded by an experienced cardiologist (D.L.) according to the extent and width of the color Doppler regurgitant jet visualized with transesophageal echocardiography and categorized as none $(0)$, trace $(0.5+)$, mild $(1+)$, moderate $(2+)$, moderate-severe $(3+)$, or severe $(4+) .{ }^{14}$ The data acquisition sequences labeled "ischemia" were started as soon as moderate IMR was observed (45-90 seconds after occlusion).

All animals received humane care in compliance with the "Principles of Laboratory Animal Care" formulated by the National Society for Medical Research and the "Guide for Care and Use of Laboratory Animals" prepared by the National Academy of Sciences and published by the National Institutes of Health (DHEW NIHG publication no. 85-23, revised 1985). This study was approved by the Stanford University Medical School Laboratory Research Animal Review committee and conducted according to Stanford University policy.

\section{Data Acquisition}

A Philips Optimus 2000 biplane Lateral ARC 2/poly DIAGNOST C2 system (Philips Medical Systems, Pleasanton, Calif) was used to record biplane videofluoroscopic images at $60 \mathrm{~Hz}$ with the animal in the right lateral decubitus position and ventilation arrested at end expiration. Two-dimensional images from each of the 2 radiographic views (right anterior oblique and left anterior oblique) were digitized by using custom software and merged to yield 3-dimensional (3-D) coordinates for each radiopaque marker every $16.7 \mathrm{~ms}$, with an accuracy of $0.1 \pm 0.3 \mathrm{~mm}$ compared with known marker-to-marker 3-D lengths. ${ }^{15}$ Analog LV pressure and electrocardiographic voltage were digitized and recorded simultaneously with the marker images. 

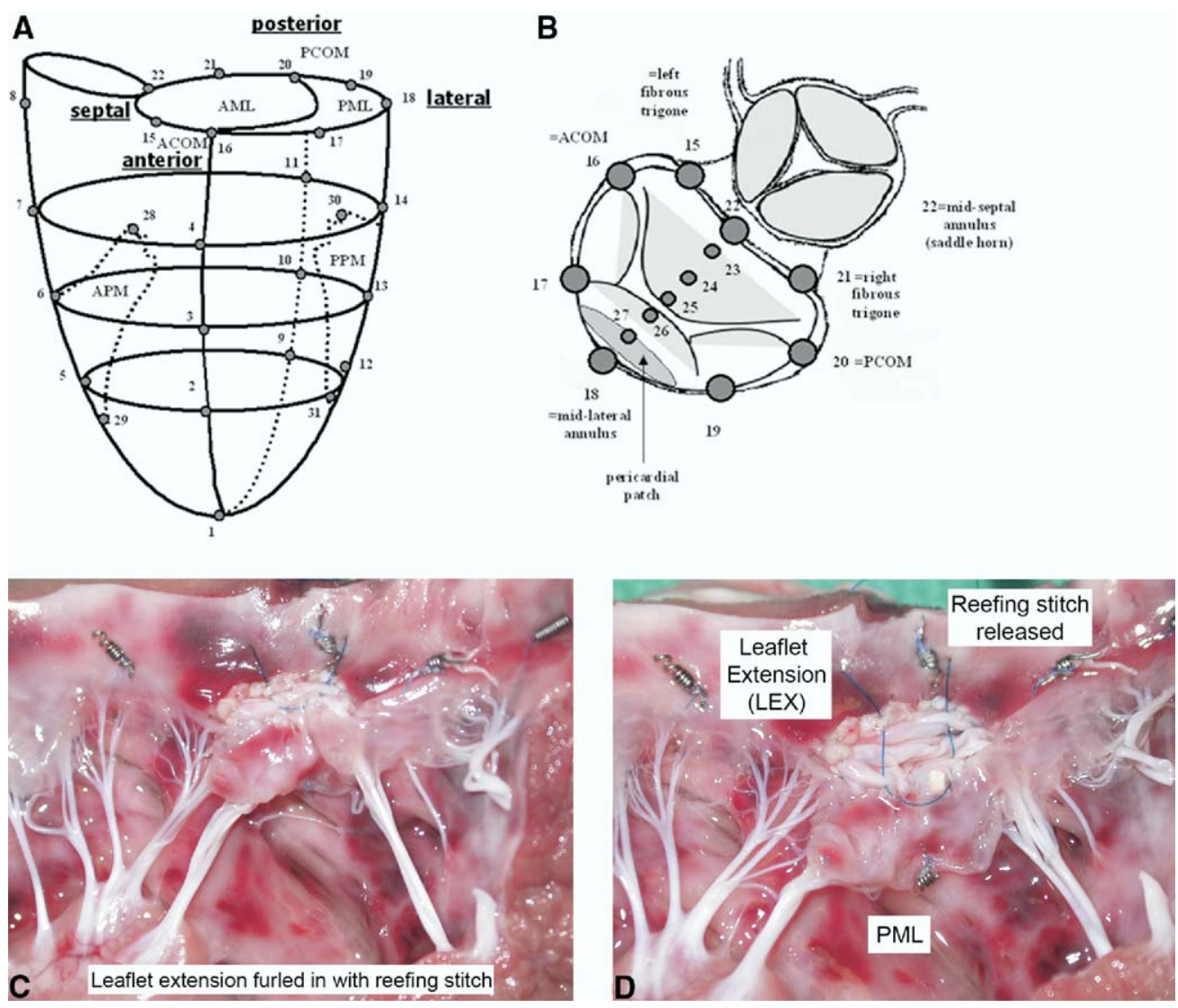

Figure 1. A, Schematic representation of the radiopaque marker array used in this study. AML, Anterior mitral leaflet; PML, posterior mitral leaflet; $A C O M$, anterior commissure; PCOM, posterior commissure; $A P M$, anterior papillary muscle; $P$ PM, posterior papillary muscle. B, Schematic representation of the annular and leaflet markers array. The pericardial patch was placed close to the annulus in the middle scallop of the posterior mitral leaflet. ACOM, Anterior commissure; PCOM, posterior commissure. C, This photograph depicts the posterior mitral annulus and posterior mitral leaflet with sutured markers in situ. The middle scallop of the posterior mitral leaflet was detached from the annulus, and a patch of autologous pericardium was sewn into this defect to extend the leaflet. The patch was initially retracted with a reefing stitch. D, Patch unfurled by release of the reefing stitch. $P M L$, Posterior mitral leaflet.

\section{Data Analysis}

Cardiac cycle timing and hemodynamics. For each cardiac cycle, end systole was defined as the videofluroscopic frame immediately before the peak rate of change of falling LV pressure $(-\mathrm{dP} / \mathrm{dt})$ and end diastole as the frame containing the maximum positive second time derivative of LV pressure corresponding with the frame immediately before the upstroke of the LV pressure curve. Instantaneous LV volume was calculated for each frame from the epicardial LV and mitral annular markers by using a space-filling multiple tetrahedral model constructed from the marker coordinates and corrected for LV convexity. ${ }^{16}$

Mitral annular geometry. Mitral annular area was calculated as the sum of the areas of 8 triangles formed by consecutive adjacent marker pairs on the annulus (nos. 15-22; Figure 1, $B$ ) and the annular centroid, without assumption of planar geometry. Annular septal-lateral diameter was calculated as the distance in
3-D space between the 2 markers placed in the middle of the septal and lateral mitral annulus (nos. 22 and 18; Figure 1, B).

PML geometry. To characterize precisely the end-systolic position of the PML with respect to the mitral annulus, 3-D marker coordinates were transformed from their original laboratory reference system to a right-handed Cartesian coordinate system with the origin at the midseptal annulus (saddle horn, marker no. 22; Figure $1, A$ and $B$ ), the positive lateral axis directed toward the midlateral annulus (marker no. 18), the positive apical axis passing through the LV apex (marker no. 1), and the positive posterior axis directed toward the posterior commissure.

The length of the pericardial patch was defined as the distance between the midlateral annulus marker (no. 18; Figure 1, B) and the patch edge marker (no. 27). Leaflet midline length was calculated as the sum of patch width and the distance between the PML free edge marker (no. 26; Figure 1, B) and the patch edge marker 
TABLE 1. Hemodynamic data

\begin{tabular}{|c|c|c|c|c|}
\hline & Preischemia & Ischemia & LEX & ANOVA \\
\hline $\mathrm{HR}\left(\min ^{-1}\right)$ & $128 \pm 5$ & $128 \pm 5$ & $129 \pm 4$ & $P=\mathrm{NS}$ \\
\hline $\mathrm{dP} / \mathrm{dt}_{\max }\left(\mathrm{mm} \mathrm{Hg} \cdot \mathrm{s}^{-1}\right)$ & $2784 \pm 467^{*}$ & $1936 \pm 242$ & $1600 \pm 214$ & $P<.001$ \\
\hline LVESV (mL) & $172 \pm 16$ & $178 \pm 15$ & $183 \pm 16$ & $P=.03$ \\
\hline LVEDV (mL) & $224 \pm 18$ & $225 \pm 17$ & $229 \pm 17$ & $P=.03$ \\
\hline LVESP $(\mathrm{mm} \mathrm{Hg})$ & $88 \pm 9 *$ & $69 \pm 4$ & $66 \pm 5$ & $P=.001$ \\
\hline LVEDP $(\mathrm{mm} \mathrm{Hg})$ & $11 \pm 6^{*}$ & $21 \pm 2$ & $22 \pm 2$ & $P=.006$ \\
\hline $\mathrm{MR}$ & $0.9 \pm 0.3^{*}$ & $2.4 \pm 0.3$ & $1.5 \pm 0.3^{*}$ & $P=.002$ \\
\hline
\end{tabular}

Values are presented as means \pm standard error of the mean. $L E X$, Leaflet extension; ANOVA, analysis of variance; $H R$, heart rate; $L V E S V$, left ventricular end-systolic volume; $L V E D V$, left ventricular end-diastolic volume; $L V E S P$, left ventricular end-systolic pressure; $L V E D P$, left ventricular end-diastolic pressure; $M R$, mitral regurgitation. $* P<.05$ versus ischemia, repeated-measures analysis of variance with the Dunnet post-hoc test.

(no. 27). PML middle scallop area was calculated as the sum of the areas of 4 triangles formed by consecutive adjacent marker pairs and the centroid (nos. 26, 17, 18, and 19; Figure 1, B).

\section{Statistical Analysis}

All data are reported as means \pm 1 standard error of the mean. Hemodynamic and marker-derived data from 2 consecutive steady-state beats were time aligned at end systole, and data from these beats were averaged for each animal and data acquisition run. Comparisons between the different conditions were made by using repeated-measures analysis of variance (ANOVA) after normal distribution had been established with the Kolmogorov-Smirnov test. If non-Gaussian data distribution was encountered, Friedman repeated-measures ANOVA on ranks was applied. If ANOVA yielded a significant $\mathrm{F}$ value $(P<.05)$, the Dunnett test was applied for post-hoc testing, with ischemia as the control condition.

\section{Results}

Table 1 summarizes group mean hemodynamic data for the preischemia, ischemia, and LEX conditions. During ischemia, IMR occurred, LV end-diastolic pressure increased significantly, and LV dP/dt and LV end-systolic pressure decreased. During LEX, neither heart rate, LV volumes, nor pressures changed, despite ongoing ischemia. MR, however, was less after LEX (control, $0.9 \pm 0.3^{*}$; ischemia, $2.4 \pm 0.3 ; \mathrm{LEX}, 1.5 \pm 0.3 * ; * P=.002)$ compared with ischemia.

Ischemia resulted in mitral annular dilatation, as reflected by increased end-systolic mitral annular area and end-systolic septal-lateral annular diameter (Table 2). LEX increased end-systolic patch length, PML midline length, and PML middle scallop area (Table 3).
Figures 2 and 3 show the changes in PML geometry. During ischemia, the lateral annulus moved laterally (Figure 2), and the PML edge was tethered apically by $0.09 \pm 0.03 \mathrm{~cm}$, which is indicative of Carpentier Type IIIb restricted systolic leaflet closing motion (Figures 2 and 3). With LEX, the patch edge moved toward the septum as patch length increased (Figure 2), and the leaflet edge marker moved further apically $(0.14 \pm 0.03 * \mathrm{~cm}, P<.001)$ as leaflet length increased (Figure 3). Even though LEX exacerbated LT, IMR was reduced, probably because of increased leaflet coaptation height and area.

\section{Discussion}

These findings show that patch extension of the PML reduces the degree of IMR, even in the absence of concomitant annular reduction, in an ovine model of acute IMR. Rather than ameliorating LT as hypothesized, however, LEX worsened systolic PML apical restriction. Although LEX might improve leaflet coaptation by augmenting leaflet area, especially if combined with RA, the clinical utility of this technically complex adjunct remains to be defined.

Aggressive treatment of IMR is based on the fact that IMR is not a benign condition: it carries a 2-fold excess mortality of $62 \%$ at 5 years in postinfarction patients, irrespective of other risk factors. ${ }^{2}$ In addition, IMR is probably a progressive disorder in which MR-related LV volume overload promotes or exacerbates further LV postinfarction remodeling, which leads to worsening MR. Mitral valve repair, rather than replacement, is the procedure of choice for patients with most forms of MR, and RA has evolved to

TABLE 2. Mitral annular parameters

\begin{tabular}{|c|c|c|c|c|}
\hline & Preischemia & Ischemia & LEX & ANOVA \\
\hline End-systolic septal-lateral diameter $(\mathrm{cm})$ & $2.55 \pm 0.15^{*}$ & $2.94 \pm 0.15$ & $3.07 \pm 0.18^{*}$ & $P<.001$ \\
\hline End-systolic mitral-annular area $\left(\mathrm{cm}^{2}\right)$ & $7.47 \pm 1.00^{*}$ & $8.91 \pm 0.97$ & $9.48 \pm 1.03^{*}$ & $P<.001$ \\
\hline
\end{tabular}

Values are presented as means \pm standard error of the mean. $L E X$, Leaflet extension; ANOVA, analysis of variance. $* P<.05$ vs ischemia, repeated-measures analysis of variance with the Dunnet post-hoc test. 
TABLE 3. Posterior mitral valve leaflet parameter associated with leaflet extension

\begin{tabular}{|c|c|c|c|c|}
\hline & Preischemia & Ischemia & LEX & ANOVA \\
\hline End-systolic patch length (cm) & $0.57 \pm 0.05$ & $0.57 \pm 0.05$ & $1.04 \pm 0.10^{*}$ & $P<.001$ \\
\hline End-systolic PML midline length $(\mathrm{cm})$ & $1.45 \pm 0.09$ & $1.53 \pm 0.10$ & $1.83 \pm 0.13^{*}$ & $P<.001$ \\
\hline End-systolic middle scallop area $\left(\mathrm{cm}^{2}\right)$ & $1.66 \pm 0.20^{*}$ & $1.91 \pm 0.22$ & $2.36 \pm 0.22^{*}$ & $P=.006$ \\
\hline
\end{tabular}

Values are presented as means \pm standard error of the mean. $L E X$, Leaflet extension; ANOVA, analysis of variance; $P M L$, posterior mitral leaflet. $* P<$ .05 versus ischemia, repeated-measures analysis of variance with the Dunnet post-hoc test.

become the key procedure for patients with IMR, aiming to reduce the size of the dilated mitral annulus to improve leaflet coaptation. Although RA improves coaptation by restoring septal-lateral annular diameter, it frequently does not sufficiently correct LT in patients with severe Carpentier type IIIb restricted systolic leaflet motion. ${ }^{4}$ To address this problem, Bolling and colleagues ${ }^{17}$ first demonstrated the utility of undersized RA for patients with functional MR as an annular solution to a ventricular problem, addressing both the MR and the ventricular dilation. Recently, favorable results have been reported in patients with IMR after such restrictive RA, with minimal recurrent or residual MR at midterm follow-up and with reverse remodeling observed in some patients. ${ }^{7-9}$ Nevertheless, recurrent IMR has been observed in upward of $30 \%$ of patients after RA in experienced centers, irrespective of ring type or size. ${ }^{3-6}$ Even though undersized annular reduction can correct both annular and subvalvular geometry in IMR, ${ }^{10}$ such might not

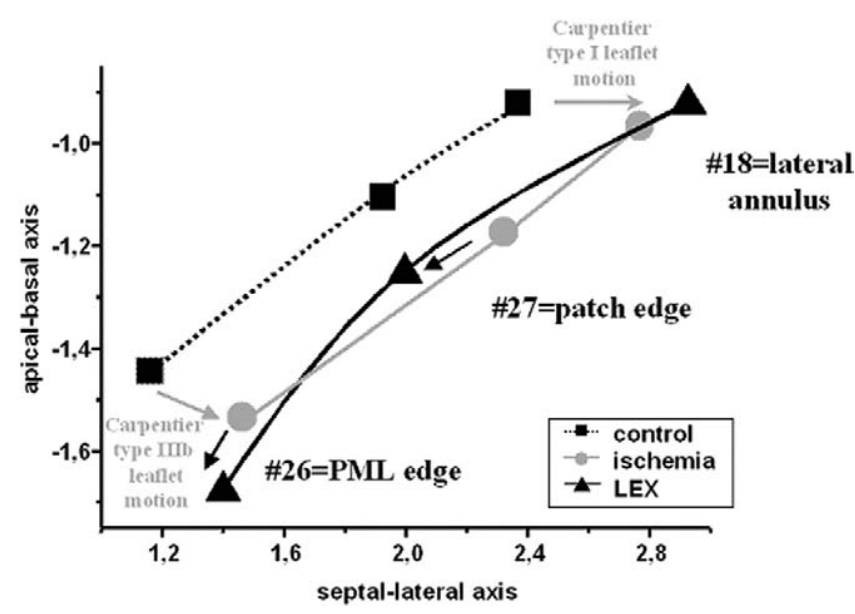

Figure 2. The coordinates of the posterior leaflet central meridian markers were projected onto a 2-dimensional plot at end systole. The mitral septal-lateral axis is on the abscissa, with the ventricular apical-basal axis on the ordinate. The lateral annular marker is seen on the upper right, with the leaflet edge marker in the lower left (numbers correspond with labeled markers, see Figure 1, $B$ ). During ischemia, the lateral annular marker moves laterally (consistent with annular septal-lateral dilation), and the leaflet edge marker is apically displaced. Leaflet extension (LEX) increases effective leaflet length. PML, Posterior mitral leaflet. sufficiently correct the subvalvular problem in patients with continued LV dilation and remodeling. ${ }^{4,5}$

Based on the mechanistic insights gained from recurrent IMR after RA, several techniques have been proposed as either adjuncts or alternatives to RA. These techniques seek to improve leaflet coaptation by minimizing LT and correcting PPM displacement by addressing either the leaflets
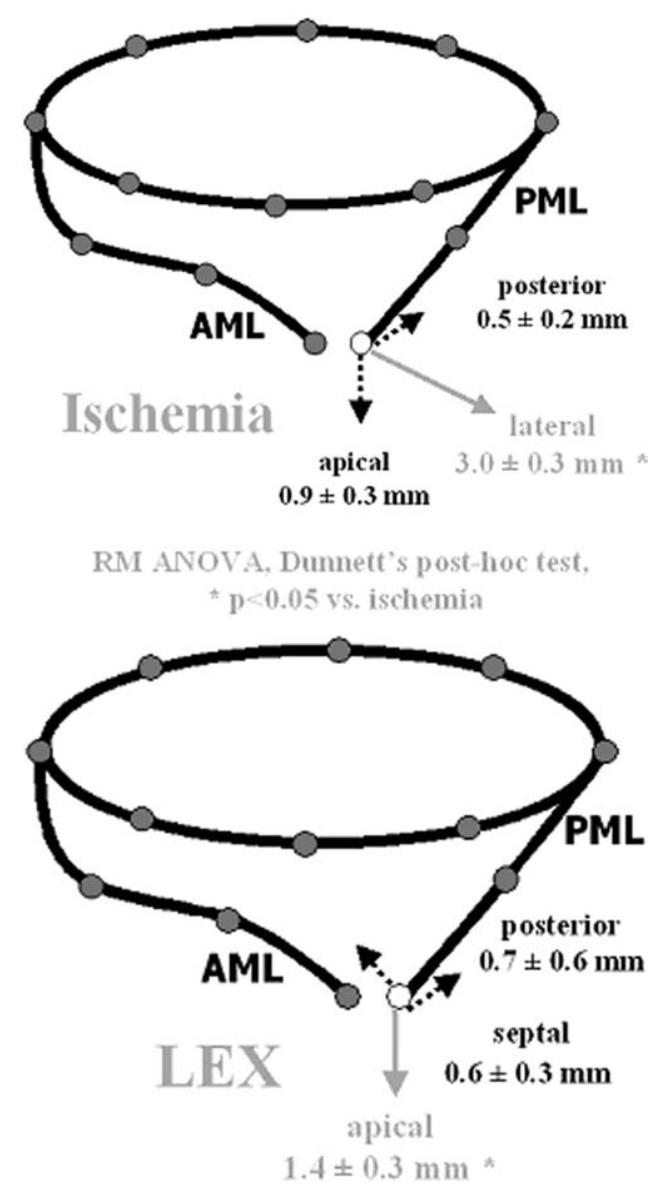

Figure 3. Schematic representation of the end-systolic posterior mitral leaflet edge displacement during ischemia and after leaflet extension (LEX). Significant shifts are shown in gray. Data are shown as means \pm standard error of the mean $\left({ }^{*} P<.05\right.$, repeatedmeasures analysis of variance with the Dunnett post-hoc test vs ischemia). AML, Anterior mitral leaflet; PML, posterior mitral leaflet. 
or the subvalvular geometry. Most proposed interventions have been developed in experimental animals and aim at restoring subvalvular geometry through infarct placation, ${ }^{18}$ infarct restraint with an external mesh patch, ${ }^{19}$ or external papillary muscle repositioning with an epicardial inflatable balloon. ${ }^{20}$ Internal papillary muscle repositioning has also been clinically described. ${ }^{21,22}$ In addition, the Coapsys device (Myocor Inc, Maple Grove, Minn), which has recently been introduced to both reduce annular septal-lateral diameter and relocate the PPM, is currently under investigation in clinical trials (RESTOR-MV, TRACE).

Messas and associates ${ }^{23}$ focused on the leaflets and reported improved leaflet coaptation after cutting the secondorder chordae, but such chordal cutting has been shown to decrease global LV systolic function and fails to consistently correct IMR. ${ }^{24}$ Moreover, deterioration in LV systolic pump performance after chordal cutting, which is due to disruption of valvular-ventricular interaction, ${ }^{25}$ would probably be poorly tolerated in patients with IMR with previous infarction and impaired preoperative LV systolic function. The Alfieri edge-to-edge technique also addresses the mitral leaflets and seeks to improve coaptation by connecting both leaflets, creating a "double-orifice" mitral opening ${ }^{26}$; however, without concomitant annular reduction, this techniques fails to reduce IMR. ${ }^{27}$ Moreover, the use of this technique in patients with IMR yielded discouraging midterm results in a Cleveland Clinic report. ${ }^{28}$

LEX has also been reported in patients with IMR. Dobre and coworkers ${ }^{12}$ reported successful use of LEX in 2 patients with IMR, wherein an autologous pericardial patch was used to extend the PML in conjunction with undersized RA. On the other hand, Kincaid and colleagues ${ }^{29}$ reported successful patch augmentation of the AML in 25 patients with IMR. Despite these reports, however, LEX has seldom been used in patients with IMR, in contrast to rheumatic mitral disease with leaflet retraction, in which patch extension of the leaflets is established. ${ }^{11}$ To enhance mechanistic insight, we evaluated LEX in an experimental setting of acute IMR. We found that LEX moderately improved IMR, even without concomitant annular reduction, but also exacerbated PML edge apical tethering.

How did PML extension reduce IMR? Mitral valve closure is a well-orchestrated interaction of all involved structures of the mitral apparatus, including the mitral annulus, leaflets, chordae, papillary muscles, and left ventricle. Specifically, mitral leaflet edge position in 3-D space is determined by connections to the annulus and papillary muscles. ${ }^{30}$ For example, if the papillary muscle tips and the lateral annulus represent the centers of 3 spheres, and the leaflet and chordal lengths represent the radii of these spheres, the position of the PML edge will be at a point where the 3 spheres intersect (Figure 4). If the centers (ie, annulus and papillary muscle tip) are displaced, the radii (ie, chordal length

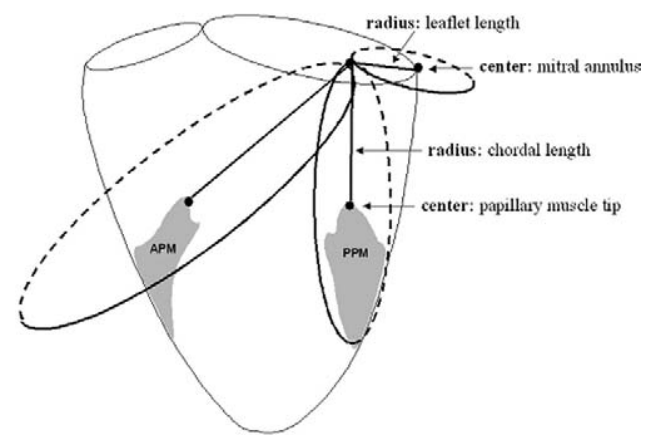

Figure 4. Concept of intersecting spheres with respect to predicted end-systolic leaflet 3-dimensional geometric configuration. Leaflet edge position is determined by 3 intersecting spheres of associated anatomic structures. The papillary muscle tips and the mitral annulus define the centers of the spheres, whereas chordal length and leaflet length define the radii. APM, Anterior papillary muscle; PPM, posterior papillary muscle.

and leaflet length) must compensate to achieve leaflet coaptation. Although surgically manipulating first-order (primary) chordal length would be delicate and technically demanding, increasing PML midline length and area by means of PML patch extension is straightforward.

In this experiment PML extension decreased IMR, despite progressive annular dilatation during ongoing ischemia, but increased leaflet length was also associated with increased apical restriction of the PML free-edge (Figure 2). This tethering effect can be explained by the increased tension of all the chordae on the mitral leaflets caused by PPM dislocation during ischemia. PML patch extension in this experiment was accomplished while preserving the attachments of the second-order chordae on the leaflet side of the incision; annular-papillary continuity was therefore preserved. By increasing the length of the PML while keeping the second-order and marginal chordae on the leaflet side, however, this technique would tend to encourage further displacement of the leaflet edge into the ventricular cavity (Figure 1,D). Based on this mechanism, we speculate that PML extension might further enhance leaflet coaptation, with improved leaflet coaptation height when combined with RA, although annular reduction was not used in this experiment.

In the current ovine model the pericardial patch was sewn into the PML central scallop because the anterolateral and posteromedial scallops are extremely small and poorly defined in sheep. In the clinical setting, however, we would advocate that the patch should augment the posteromedial (Carpentier P3) scallop, ${ }^{12}$ because the IMR leak is usually located more toward the posterior commissure in patients. The size of the pericardial patch has to be tailored individually to each patient on the basis of intraoperative assess- 
ment. Although we cannot speculate on the durability of this type of repair in the clinical IMR setting, patch extension of mitral leaflets is an established technique in rheumatic mitral disease. An additional concern with the use of LEX is LV outflow tract obstruction caused by systolic anterior movement (SAM) of the AML, which is rare after mitral valve repair but might occur after major downsizing of the mitral annulus. Even though annular reduction was not used in this acute experiment, we chose to focus on PML extension for this reason. In the setting of chronic IMR, however, the danger of SAM is probably nonexistent because of the increased aortomitral angle that results from ventricular dilation in these patients. Recent studies have documented no SAM after restrictive annuloplasty for IMR. ${ }^{8}$

Although LEX might help increase leaflet coaptation by augmenting leaflet area to compensate for PML apical restriction (Table 2), it fails to address the underlying ventricular pathology in IMR. Because combined coronary revascularization and RA is required in most patients, the additional complexity of LEX will significantly prolong crossclamp time, thereby limiting its clinical utility. When we contrast this procedure with our previous concept of papillary muscle repositioning using a transventricular suture (STRING technique) from the PPM tip to the right fibrous trigone, ${ }^{31}$ we would favor the STRING technique because of its simplicity, rapidity, ability to be adjusted after weaning from bypass, and similar improvement of IMR. Like Kron and colleagues, ${ }^{21}$ who have advocated such surgical relocation of the PPM, the STRING technique allows direct manipulation of the subvalvular geometry under echocardiographic guidance after undersized RA to reduce LT by bringing the PPM closer to the midseptal annulus (ie, the anterior mitral annular saddle horn). The transventricular suture then sets the tethering length between the midseptal annulus and PPM tip to help prevent recurrent PPM dislocation caused by progressive postinfarction $\mathrm{LV}$ dilatation.

Several important study limitations should be mentioned. These data were obtained in an acute, open-chest setting in normal sheep hearts immediately after an open cardiac surgical procedure, and therefore direct extrapolation of these findings to human subjects must be done with caution. The investigation of acute IMR in open-chest sheep is different from the clinical scenario of chronic IMR. Although we studied the efficacy of LEX in the setting of acute IMR, the mechanisms described are probably similar in the chronic IMR context. Septal-lateral mitral annular dilation is important in both acute ${ }^{32}$ and chronic $^{33}$ IMR' and similar alterations in subvalvular geometry characterized by posterior, lateral, and basal displacement of the PPM causing posterior leaflet apical displacement occur during acute ischemia, ${ }^{32}$ although not as pronounced as after chronic posterior infarction. ${ }^{33}$ These similarities support the use of an acute ischemia model to test the efficacy of LEX. Consistent with these previous studies of acute and chronic IMR, increased end-systolic mitral annular septal-lateral diameter and area were observed during ischemia. However, because of the experimental design, wherein data were acquired at baseline and then during proximal circumflex ischemia and during ongoing ischemia after release of the patch-reefing suture, it is not possible to discern whether the progressive annular dilatation observed between ischemia and LEX conditions was due to ongoing ischemia or possibly augmented by unfurling of the reefing stitch (which might have been serving as a regional annular plication). Similarly, the worsening of $\mathrm{dP} / \mathrm{dt}$ and end-systolic and enddiastolic pressures and volumes after LEX might reflect this experimental design (Table 1), wherein data after LEX were acquired during prolonged ischemia (after acquisition of the ischemia data) in all animals. Nevertheless, LEX was associated with decreased MR in all animals, even without concomitant annular reduction, despite ongoing ischemia. Differences in comparative anatomy between human and sheep mitral valve and subvalvular anatomy might also be important. Sheep might have a relatively small leaflet/ annular area ratio, which makes them more susceptible to smaller increases in annular area compared with human subjects. Ultimately, future studies in a chronic IMR model are required to assess the efficacy of this patch repair technique in conjunction with RA.

We appreciate the superb technical assistance provided by Maggie Brophy, AS; Katha Gazda, BA; and Mark Grisedale, DVM.

\section{References}

1. Bursi F, Enriquez-Sarano M, Nkomo VT, Jacobsen SJ, Weston SA, Meverden RA, et al. Heart failure and death after myocardial infarction in the community: the emerging role of mitral regurgitation. Circulation. 2005;111:295-301.

2. Grigioni F, Enriquez-Sarano M, Zehr KJ, Bailey KR, Tajik AJ. Ischemic mitral regurgitation: long-term outcome and prognostic implications with quantitative Doppler assessment. Circulation. 2001;103: 1759-64.

3. Tahta SA, Oury JH, Maxwell JM, Hiro SP, Duran CM. Outcome after mitral valve repair for functional ischemic mitral regurgitation. J Heart Valve Dis. 2002;11:11-8.

4. Hung J, Papakostas L, Tahta SA, Hardy BG, Bollen BA, Duran CM, et al. Mechanism of recurrent ischemic mitral regurgitation after annuloplasty: continued LV remodeling as a moving target. Circulation. 2004;110(suppl 1):II85-90.

5. Matsunaga A, Tahta SA, Duran CM. Failure of reduction annuloplasty for functional ischemic mitral regurgitation. J Heart Valve Dis. 2004; 13:390-7.

6. McGee EC, Gillinov AM, Blackstone EH, Rajeswaran J, Cohen G, Najam F, et al. Recurrent mitral regurgitation after annuloplasty for functional ischemic mitral regurgitation. J Thorac Cardiovasc Surg. 2004;128:916-24.

7. Bax JJ, Braun J, Somer ST, Klautz R, Holman ER, Versteegh MI, et al. Restrictive annuloplasty and coronary revascularization in ischemic mitral regurgitation results in reverse left ventricular remodeling. Circulation. 2004;110(suppl 1):II103-8.

8. Braun J, Bax JJ, Versteegh MI, Voigt PG, Holman ER, Klautz RJ, et al. Preoperative left ventricular dimensions predict reverse remodeling 
following restrictive mitral annuloplasty in ischemic mitral regurgitation. Eur J Cardiothorac Surg. 2005;27:847-53.

9. Geidel S, Lass M, Schneider C, Groth G, Boczor S, Kuck KH, et al. Downsizing of the mitral valve and coronary revascularization in severe ischemic mitral regurgitation results in reverse left ventricular and left atrial remodeling. Eur J Cardiothorac Surg. 2005;27:1011-6.

10. Tibayan FA, Rodriguez F, Langer F, Liang D, Daughters GT, Ingels NB, et al. Mitral suture annuloplasty corrects both annular and subvalvular geometry in acute ischemic mitral regurgitation. J Heart Valve Dis. 2004;13:414-20.

11. Acar C, de Ibarra JS, Lansac E. Anterior leaflet augmentation with autologous pericardium for mitral repair in rheumatic valve insufficiency. J Heart Valve Dis. 2004;13:741-6.

12. Dobre M, Koul B, Rojer A. Anatomic and physiologic correction of the restricted posterior mitral leaflet motion in chronic ischemic mitral regurgitation. J Thorac Cardiovasc Surg. 2000;120:409-11.

13. Zhu F, Otsuji Y, Yotsumoto G, Yuasa T, Ueno T, Yu B, et al. Mechanism of persistent ischemic mitral regurgitation after annuloplasty: importance of augmented posterior mitral leaflet tethering. Circulation. 2005;112(suppl):I396-401.

14. Helmcke F, Nanda NC, Hsiung MC, Soto B, Adey CK, Goyal RG, et al. Color Doppler assessment of mitral regurgitation with orthogonal planes. Circulation. 1987;75:175-83.

15. Daughters GT, Sanders WJ, Miller DC, Schwartzkopf A, Mead CW, Ingels NB Jr. A comparison of two analytical systems for threedimensional reconstruction from biplane videoradiograms. Proc Comp Cardiol (IEEE). 1988;15:79-82.

16. DeAnda A Jr, Moon MR, Nikolic SD, Castro LJ, Fann JI, Daughters GT, et al. A method to assess endocardial regional longitudinal curvature of the left ventricle. Am J Physiol. 1995;268(suppl):H2553-60.

17. Bolling SF, Pagani FD, Deeb GM, Bach DS. Intermediate-term outcome of mitral reconstruction in cardiomyopathy. $J$ Thorac Cardiovasc Surg. 1998;115:381-6.

18. Liel-Cohen N, Guerrero JL, Otsuji Y, Handschumacher MD, Rudski LG, Hunziker PR, et al. Design of a new surgical approach for ventricular remodeling to relieve ischemic mitral regurgitation: insights from 3-dimensional echocardiography. Circulation. 2000;101: 2756-63.

19. Moainie SL, Guy TS, Gorman JH III, Plappert T, Jackson BM, John-Sutton MG, et al. Infarct restraint attenuates remodeling and reduces chronic ischemic mitral regurgitation after postero-lateral infarction. Ann Thorac Surg. 2002;74:444-9.

20. Hung J, Guerrero JL, Handschumacher MD, Supple G, Sullivan S, Levine RA. Reverse ventricular remodeling reduces ischemic mitral regurgitation: echo-guided device application in the beating heart. Circulation. 2002;106:2594-600.

21. Kron IL, Green GR, Cope JT. Surgical relocation of the posterior papillary muscle in chronic ischemic mitral regurgitation. Ann Thorac Surg. 2002;74:600-1.

22. Hvass U, Tapia M, Baron F, Pouzet B, Shafy A. Papillary muscle sling: a new functional approach to mitral repair in patients with ischemic left ventricular dysfunction and functional mitral regurgitation. Ann Thorac Surg. 2003;75:809-11.

23. Messas E, Pouzet B, Touchot B, Guerrero JL, Vlahakes GJ, Desnos M, et al. Efficacy of chordal cutting to relieve chronic persistent ischemic mitral regurgitation. Circulation. 2003;108(suppl 1):II111-5.

24. Rodriguez F, Langer F, Harrington KB, Tibayan FA, Zasio MK, Liang $\mathrm{D}$, et al. Cutting second-order chords does not prevent acute ischemic mitral regurgitation. Circulation. 2004;110(suppl 1):II91-7.

25. Yun KL, Fann JI, Rayhill SC, Nasserbakht F, Derby GC, Handen CE, et al. Importance of the mitral subvalvular apparatus for left ventricular segmental systolic mechanics. Circulation. 1990;82(suppl):IV89-104.

26. Alfieri O, Maisano F, De Bonis M, Stefano P, Torracca L, Oppizzi M, et al. The double-orifice technique in mitral valve repair: a simple solution for complex problems. J Thorac Cardiovasc Surg. 2001;122: 674-81.

27. Timek TA, Nielsen SL, Lai DT, Tibayan FA, Liang D, Rodriguez F, et al. Edge-to-edge mitral valve repair without ring annuloplasty for acute ischemic mitral regurgitation. Circulation. 2003;108(suppl 1): II122-7.
28. Bhudia SK, McCarthy PM, Smedira NG, Lam BK, Rajeswaran J, Blackstone EH. Edge-to-edge (Alfieri) mitral repair: results in diverse clinical settings. Ann Thorac Surg. 2004;77:1598-606.

29. Kincaid EH, Riley RD, Hines MH, Hammon JW, Kon ND. Anterior leaflet augmentation for ischemic mitral regurgitation. Ann Thorac Surg. 2004;78:564-8.

30. Dagum P, Timek TA, Green GR, Lai D, Daughters GT, Liang DH, et al. Coordinate-free analysis of mitral valve dynamics in normal and ischemic hearts. Circulation. 2000;102(suppl 3):III62-9.

31. Langer F, Rodriguez F, Ortiz S, Cheng A, Nguyen TC, Zasio MK, et al. Subvalvular repair: the key to repairing ischemic mitral regurgitation? Circulation. 2005;112(suppl):I383-9.

32. Lai DT, Timek TA, Tibayan FA, Green GR, Daughters GT, Liang D, et al. The effects of mitral annuloplasty rings on mitral valve complex 3 -D geometry during acute left ventricular ischemia. Eur $J$ Cardiothorac Surg. 2002;22:808-16.

33. Tibayan FA, Rodriguez F, Zasio MK, Bailey L, Liang D, Daughters GT, et al. Geometric distortions of the mitral valvular-ventricular complex in chronic ischemic mitral regurgitation. Circulation. 2003; 108:II116-21.

\section{Discussion}

Dr Robert C. Gorman (Philadelphia, $\mathrm{Pa}$ ). Frank, I want to congratulate you on an excellent presentation and interesting experiment. The intellectual and physical fortitude required to perform these kinds of experiments is substantial.

IMR is a humbling problem for surgeons, one where we fail our patients on several levels. First of all, as you have alluded to, we are not nearly as good as we think we are at eliminating IMR. Studies like the ones you have presented and others performed by your group in the past are valuable, if for no other reason than that they draw attention to the inadequacies of our established techniques and therefore stimulate interest in developing new approaches.

Because of our own experimental studies, as well as a critical and in-depth review of all the existing literature, we have become very pessimistic about the value of any surgical approach to chronic IMR. Even for patients in whom a durable repair is achieved or the valve is replaced, the heart often remains dilated, and longevity is very rarely improved. These sobering facts have led us to think of IMR not as a primary pathology but really as a manifestation of end-stage and irreversible infarction-induced ventricular remodeling.

We believe that the true challenge for surgeons and cardiologists in the 21st century is the development of strategies designed to be implemented early after infarction that are intended to prevent rather than to reverse infarction-induced remodeling.

I have 2 questions regarding the data you have presented today.

First, does the inherent instability of the animal preparation that you have used, the difficulty in doing quantitative transesophageal echocardiography in sheep, the nontrivial baseline MR, and the residual MR after LEX affect the confidence you have in your conclusions?

Second, and more importantly, your group and others have characterized the mechanism of acute and chronic IMR in the sheep model. The mechanism for these manifestations of ventricular remodeling is really quite different. Because chronic IMR is the critical problem faced by surgeons, why did you choose to study the acute IMR model? What implications do your findings have for the treatment of chronic IMR?

Dr Langer. The acute IMR in this model was induced by proximal circumflex occlusion. Of course we lost some of the 
animals because of malignant arrhythmias. The ischemia data run was usually started between 45 and 70 seconds after the onset of ischemia. We started the run as soon as moderate MR was observed on transesophageal echocardiography; most of the animals had moderate or severe MR. I have to admit that patch retraction might have induced some structural MR (baseline MR grade of $0.9)$, but this went up to 2.4 during ischemia. The acute IMR was reduced by about 1 grade with LEX. We did not eliminate the IMR completely, but we speculate that LEX in conjunction with RA might help in selected patients.

Referring to your second question, you are correct. We initially evaluated this technique in the acute setting as a pilot experiment. This is our standard approach in exploring new repair concepts to keep costs and animal attrition down. The mechanisms responsible for the IMR in the acute and the chronic context are surprisingly not all that dissimilar; it is primarily just a difference in the magnitude of the pathologic geometric changes that differentiates the 2 conditions. On the other hand, I agree that a chronic experimental IMR animal model better mimics the clinical setting of patients with chronic IMR caused by ischemic heart disease.

Dr Masashi Komeda (Kyoto, Japan). Congratulations on another success of the new way of treatment for IMR.

I have one question. I always follow Dr Miller's suggestion that a ventricular solution is necessary for ventricular disease, and this is obviously ventricular disease. From that viewpoint, this new method, although very elegant, for me looks a little bit like a valvular solution for ventricular disease. Of course, realistically it might be necessary, but I want to hear your opinion about that. In other words, by doing LEX, it might possibly allow the posterior wall further dilatation.

Dr Langer. Excellent question, Dr Komeda. After I moved back to Homburg, Germany, after my research in the Miller lab at Stanford, we attempted to translate these experimental approaches into clinical practice. Based on this experience, we do think that in a subset of patients, a ring is not going to be enough, and therefore we have to do something more. In fact, we did favor repositioning of the posterior papillary muscle, not only because of the simplicity of this approach but also because of what you just pointed out, that we do think that this subvalvular technique is a better approach to a ventricular disease.

Dr Robert W. M. Frater (Bronx, $N Y$ ). We all agree that we need better ventricular anterior leaflet response. But if you are going to extend the posterior leaflet to mobilize it-we know that it is immobilized in these circumstances-should you not include also the P3 area, as well as the P2 area, because a good deal of the insufficiency comes from between the scallops in this form of mitral insufficiency? And you have extended only the central area. You really need to extend the area between the commissure and the central leaflet as well, I believe. I ask your opinion on that.

Dr Langer. I totally agree with that, Dr Frater. Dr Miller usually says, "The leak is in the southeast corner." When we designed this experiment, we were stimulated by a case report by Dobre and coworkers from Sweden, who performed LEX in conjunction with an RA in 2 patients with IMR. And indeed, they placed the pericardial patch starting from the leaflet center extending into the P3 segment. In clinical practice I think this is the way to go. Sheep, however, have a sizeable middle scallop along with 2 anterolateral and posteromedial subscallops that are rudimentary and almost nonexistent. With my limited surgical skills, I was happy that I was able to put a patch in the middle scallop; I think it is nearly technically impossible to place a patch in the posteromedial scallop of an ovine posterior leaflet.

Dr Radu C. Deac (Targu-Mures, Romania). I enjoyed very much the presentation.

We used this technique back in 1982 in 33 clinical rheumatic cases. During the following years, the patch inserted in the posterior leaflet was covered with the patient's own tissue and became less pliable. The majority of valves were replaced in time because of loss of function.

There are 2 issues to be raised here. One is the technique, and the other is the type of tissue used for reconstruction.

Considering the technique, the patch should be as far as possible from the posterior insertion of the valve because if it is too close, it will cover all the wrong tissue very easily.

Second, incision in the posterior leaflet allows access to valvular structure not seen otherwise. And from the tissue point of view, it is important to be autologous and very thin. Professor Carpentier' group also published a group with this technique with autologous pericardium.

My question is this: Do you plan to do a chronic study with this technique?

Dr Langer. Our group has been looking forward to the discussion this morning. We had heard earlier from some who had read our abstract that "We have done this before, but it didn't work ...."

We wanted to take the opportunity of this discussion to find out why it did not work well in the clinical world. In our model of acute MR, it did result in moderate improvement in IMR. We are curious what the audience experienced in their patients with IMR and why LEX did not work in the long term.

We have not planned a chronic experiment yet. We wanted to generate paired data by unfurling of the leaflet in the same animal, which is probably not possible in a chronic experiment. We avoided the use of glutaraldehyde fixation or bovine pericardium because we were worried that the patch would not unfurl adequately. In a chronic experiment you would have to compare 2 different groups of animals (control vs LEX).

Dr Alain F. Carpentier (Paris, France). I rise to congratulate you for bringing to our attention what is still a challenging problem, that is to say, the management of ischemic mitral valve regurgitation.

I have been using LEX for 2 decades in restricted leaflet motion, mainly in rheumatic valvular disease, and I can confirm that provided that you use a glutaraldehyde-treated autologous pericardium, it does not shrink. Therefore this technique is appealing and works long term, both in rheumatic valve disease and congenital malformation.

Now IMR is another story. It is another story because it is a myocardial disease rather than a valvular disease. It is true that you can correct mitral valve regurgitation with LEX in IMR, but it is going to be temporary. That is the first drawback.

The second drawback is that you have to enlarge the P2-P3 segment. And in this area, particularly in ischemic mitral valve disease, the leaflet tissue is very fragile, very thin, and therefore 
you can do the operation, but it is a long-lasting and tedious one. I have done it several times, but I have abandoned using it, and I prefer to reinforce the myocardium with some sort of support so as to treat the cause of recurrent regurgitation.

Dr Langer. First of all, I have to say I feel very honored to talk about the mitral valve in the presence of Professor Carpentier. Of course I agree with what you said.

Kincaid and associates reported successful patch augmentation of the AML in a case series of 25 patients with IMR (Annals of Thoracic Surgery, 2004). We have avoided this approach because we do think there might be a chance of creating SAM. Do you have any personal experience with patch extension of the anterior leaflet for patients with IMR?

Dr Carpentier. You mean the risk of SAM?

Dr Langer. The anterior leaflet, did you extend the anterior leaflet also, or just the posterior leaflet like we did?
Dr Carpentier. I am not sure I understand properly your question.

Dr Langer. There was a group who reported augmentation of the anterior leaflet. Have you ever done that?

Dr Carpentier. Yes, I mean-

Dr Langer. For ischemics.

Dr Carpentier. You mean enlargement of the anterior leaflet?

Dr Langer. Correct. There was a case report published in the Annals-

Dr Carpentier No, it does not make sense because the tethering is located at P2-P3, mainly P3 and the commissural area. If you want to be successful in IMR, this is the area you have to enlarge, and not the anterior leaflet.

Dr Langer. Thank you. 